\title{
One more leap
}

After its new launch as a web-only and open-access international journal in 2011, Environmental Health and Toxicology $(E H T)$ gained a good reputation among scientific communities owing to the invaluable contributions of authors, readers, reviewers, and editors. The journal has been indexed in PubMed, PubMed Central, and google scholar, and I am pleased to notify you that $E H T$ will also be indexed in Scopus this year. This will be a great leap for EHT.

In addition, the Korean Society of Environmental Health and Toxicology and the Korean Society of Environmental Analysis reached an agreement in 2018 to publish EHT together to enable us to attract articles from environmental experts from a broader spectrum. After being indexed in Scopus, the new journal title will be Environmental Analysis, Health and Toxicology $(E A H T)$. The scope of the journal now covers wider areas in biological and chemical analysis concerning the environment, including environmental chemistry and exposure to chemicals, ecotoxicology and ecological risks, human toxicology, risk assessment, environmental health, and policy. The editorial board will be reinforced with not only Korean but global experts.

Ours has been a great success in a very short time, transforming from a modest domestic journal to a broader international journal. As the Editor-in-Chief of EHT, I am deeply indebted to all our contributors. The goals of EHT as a leading academic journal have always been to provide a place to share ideas, distribute new scientific findings, and develop environmental management strategies. I humbly request that you continue to submit good manuscripts, give scientific and timely reviews, and cite relevant articles to publish so that we can continue our important mission.

Jung-Hwan Kwon

http://orcid.org/0000-0002-6341-7562

Editor-in-Chief Environmental Health and Toxicology Division of Environmental Science and Ecological Engineering, Korea University, Seoul, Korea 